\title{
Some shear tests on reinforced concrete beams without shear reinforcement*
}

\author{
by R. Taylor, B.Sc., D.I.C., A.M.I.C.E.
}

Contribution by C. B. Wilby, Ph.D., B.Sc.,

A.M.I.C.E., A.M.I.Struct.E. (University of Shefficld)

I am pleased to see a paper reinforcing my views ${ }^{(1,2)}$ concerning the permissible shear stresses of CP 114 (1957). There is no doubt that trouble will be experienced if the high values permitted by the Code are used by engineers. I do not agree with the author that the Code can be justified because failures have not been experienced. I believe that failures have not been experienced in the United Kingdom because these high stresses have probably not been experienced, for the following reasons.

(I) A large proportion of structural members seldom experience their design loads.

(2) A large proportion of structures use 1:2:4 concretes for which the permissible shear stress of the Code is not dangerously high and the strength of the concrete will usually be well above the minimum requirements before the structure experiences its design loads.

(3) The high-strength concretes associated with the high shearing strengths permitted by the Code give designers small sections which are often impracticable to reinforce, and which may be such that excessive deflexions are involved.

(4) Most engineers have the good sense not to use the high shearing strengths of the present Code.

Even though the high permissible shearing strengths of the Code are probably rarely used, nevertheless the Code ought to be safe to use in these instances. This particular point has obviously been an oversight in an otherwise generally reliable Code of Practice; for, out of the considerable amount of work published before the Code on this subject, there is nothing to my knowledge which would have justified the recommendation by the Code of these high stresses. I therefore sincerely hope that a suitable amendment will be published to the Code without delay.

The paper has not considered the effect of compression reinforcement; my tests ${ }^{(3,4)}$ show that even small quantities are important and I have suggested in reference 1 a possible revised clause for the Code which includes this factor. Obviously there are many factors which should preferably be included if possible but I feel that the compression steel can be taken into account quite simply.

*Pages 145-154 of Magazine No. 36.

\author{
Contribution by Professor A. M. Neville \\ and $\mathbf{J}$. Taub $\dagger$
}

Mr Taylor has investigated a number of interesting aspects of the problem of shear in reinforced concrete beams and we are pleased to find that many of his conclusions agree with those recently reported by $\mathrm{us}^{(5)}$. This applies in particular to the influence of the percentage steel area of reinforcement on the diagonal cracking load. Likewise, we found no difference between the behaviour of beams reinforced with mild steel and that of beams reinforced with deformed bars but it is important to note that this is so only in beams without shear reinforcement: when vertical stirrups are present, the deformations improve appreciably the composite action of the beam so that the strength in shear, at least for longer shear spans, is increased.

It is a sound recommendation that the diagonal cracking load of a beam without shear reinforcement should be considered as the ultimate load. We expressed this opinion in our papers ${ }^{(5)}$ and before that this recommendation was made by Whitney ${ }^{(6)}$, the eminent American designer. This importance of the diagonal cracking load is not, however, related to the manner of loading of the beams, as suggested by $\mathrm{Mr}$ Taylor. Indeed, his tests on beams loaded direct would lead to the same conclusion.

Unfortunately, from Mr Taylor's data, it is difficult to gauge the influence of the manner of loading on the shear strength of a beam: no duplicate tests have been made, so that it is hard to distinguish between the scatter of results and real differences. In particular, the apparent very large influence of the manner of loading in beams with a shear span of 18 in. (shear span: effective depth ratio of 1.64 ) is not confirmed by our tests $^{(5)}$. Our beams with a shear span:effective depth ratio of 2.09 have shown that the strength of beams loaded or supported through nibs is between 87 and $92 \%$ of the strength of similar beams loaded and supported directly.

Furthermore, we found that beams supported at one end directly and at the other through nibs failed sometimes at one end and sometimes at the other. It does not thus seem that a beam loaded through nibs has an inherently lower strength in shear.

tAt the time of submitting this contribution, Professor Neville was at the Nigerian College of Technology (Faculty of University College, Ibadan) and Dr Taub in private practice in Tel Aviv. 
We should point out, however, that in our tests a proper connexion was provided between the main beam and the cross beams (nibs) in order to prevent the development of tension in the main beam due to the action of the cross beams. Another type of connexion was suggested by us elsewhere ${ }^{(7)}$. In our tests, the top surface of the cross beams was in the same plane as the top surface of the main beam, as would generally be the case in practice. This is in contrast to $\mathrm{Mr}$ Taylor's arrangement where there was a 3 in. difference in the level of the top surfaces of the main and cross beams: as a result, severe vertical tension stresses might be induced in the main beam immediately above the nib.

We feel that these design details are of considerable importance if we are to interpret correctly the results of laboratory tests: most tests are made on beams loaded directly, whilst in the majority of actual structures loads are applied through the medium of secondary beams framed into the main beams. The strength of these indirectly loaded main beams is lower but, when a good connexion is provided between the main beam and the cross beams, the difference is not alarming.

\section{Reply by the author}

There are, no doubt, widely differing views on whether a Code of Practice which has been proved satisfactory by the behaviour of structures designed in accordance with it should be altered to give more stringent recommendations. In my opinion, such alterations would not be justified but for the possibilities of other changes occurring in design. For instance, changes in the loading recommended for the design of different types of structure may be made from time to time as data are obtained of actual load intensities and analysed on a statistical basis. Such changes will generally be to reduce the design loads. In this way, actual loads and design loads may well be more closely identified than has been the case in the past. To ensure that structures will still perform satisfactorily, it is considered that it will be necessary to alter the present recommendations for shear in beams without shear reinforcement. On this point $\mathrm{Dr}$ Wilby and $\mathrm{I}$ are in agreement.

Professor Neville and Dr Taub have examined the effect of the manner in which a beam is loaded. With regard to the effect of the manner of loading on the ultimate load, the large difference for the beams tested with a short shear span is similar to that observed by Professor Ferguson in his tests. The smaller difference observed by Professor Neville and Dr Taub is partly due to the higher shear span to depth ratio, and partly due to their arrangement of loading. If loading on the top surface of a beam is regarded as one limit, arıd loading through the type of nib used in my tests is the other limit, then the type of loading used by Professor Neville and Dr Taub is somewhere between these limits. However, in view of the now general recognition that the stage of diagonal cracking must determine the shear-carrying capacity of a beam without shear reinforcement, and since the tests of Series 1 showed the manner of loading to have little or no effect on the diagonal cracking load, the effect of the manner of loading on ultimate loads is not only " not alarming ", it is only of academic interest. In the tests in series 2 and 3, which formed the basis for the recommendations in the paper, the beams were loaded on their top surface.

\section{REFERENCES}

1. WILBY, C. B. Permissible shear stresses of the 1957 British Code of Practice. Journal of the American Concrete Institute. Vol. 29, No. 12. June 1958. pp. 1146-1148.

2. WILBX, C. B. Research for the concrete industry. Discussion on the paper by A. R. Colins. The Structural Engineer. Vol. 38, No. 12. December 1960. p. 401.

3. WILBY, C. B. The strength of reinforced concrete beams in shear. Thesis presented to the University of Leeds for the degree of Ph.D. pp. 125.

4. WILBY, C. B. The strength of reinforced concrete beams in shear. Magazine of Concrete Research. Vol. 3, No. 7. August 1951. pp. 23-30.

5. TAUB, 3 . and NEVILLE, A. M. Resistance to shear of reinforced concrete beams. Journal of the American Concrete Institute. Vol. 32. No. 2. August 1960. pp. 193-220. No. 3. September 1960. pp. 315-336. No. 4. October 1960. pp. 443-463. No. 5. November 1960. pp. 517-532. No. 6. December 1960. pp. 715-730.

6. WHITNEY, C. S. Ultimate shear strength of reinforced concrete flat slabs, footings, beams, and frame members without shear reinforcement. Journal of the American Concrete Institute. Vol. 29, No. 4. October 1957. pp. 265-298.

7. TAUB, J. and.Neville, A. M. Shear strength of reinforced concrete beams loaded through framed-in cross-beams. 6th Congress of the International Association for Bridge and Structural Engineering, Stockholm, 27 June-1 July 1960. Preliminary Publication. pp. 77-95. 